\title{
An observational study of effect of Mullerian anomalies on pregnancy
}

\author{
Neha Raj*, Niranjan N. Chavan
}

Department of Obstetrics and Gynecology, Lokmanya Tilak Municipal Medical College and General Hospital, Mumbai, Maharashtra, India

Received: 16 January 2019

Accepted: 11 February 2019

\section{*Correspondence:}

Dr. Neha Raj,

E-mail: locateneha@gmail.com

Copyright: ( ) the author(s), publisher and licensee Medip Academy. This is an open-access article distributed under the terms of the Creative Commons Attribution Non-Commercial License, which permits unrestricted non-commercial use, distribution, and reproduction in any medium, provided the original work is properly cited.

\begin{abstract}
Background: Mullerian anomalies occur in approximately 3-4\% of fertile and infertile women, 5-10\% of women with recurrent early pregnancy loss, and up to $25 \%$ of women with late first or second-trimester pregnancy loss or preterm delivery. However, due to low prevalence rate and asymptomatic course of the anomalies, Mullerian anomalies remain underdiagnosed and often overlooked as a possible cause of recurrent pregnancy failures, preterm deliveries, IUGR and low birth weight.

Methods: Total of 30 cases of Mullerian anomalies with pregnancy, prior diagnosed or incidental during LSCS, were studied for complications during pregnancy, history of gynecological complaints and rate of diagnosis with routine imaging technique.

Results: Septate uterus was the most common anomaly seen in this study (36.6\%).56.6\% were diagnosed incidentally during LSCS despite the fact $26.6 \%$ of cases had history of 2 or more abortions and $30 \%$ had some or other gynecological complaints previously. $10 \%$ of pregnancies ended in abortions, $20 \%$ had preterm delivery, $36.6 \%$ had malpresentations and there was case of rupture uterus $(03.3 \%)$.

Conclusions: Mullerian anomalies are often asymptomatic or have subtle gynecological symptoms which are often missed by both patient and gynecologists. It is observed that due to the asymptomatic course of Mullerian anomalies, invasive nature of HSG and lack of 1.5 Tesla MRI at many institutes leads to low rate of diagnosis of Mullerian anomalies. Pregnancy with Mullerian anomalies often have preterm delivery, IUGR and malpresentation, so, require proper counselling and close monitoring during antenatal period.
\end{abstract}

Keywords: Malpresentation, Mullerian anomalies, Obstetrics complications, Preterm labour, Rupture uterus

\section{INTRODUCTION}

Normal development of the female reproductive tract involves a series of complex processes characterized by the differentiation, migration, fusion, and subsequent canalization of the Mullerian system. ${ }^{1}$ Congenital anomalies of the female reproductive tract may involve the uterus, cervix, fallopian tubes, or vagina arise from defect in development of Mullerian ducts during foetal life. As per the various studies conducted previously, uterine anomalies occur in approximately $3-4 \%$ of fertile and infertile women, 5-10\% of women with recurrent early pregnancy loss, and up to $25 \%$ of women with late first or second-trimester pregnancy loss or preterm delivery. ${ }^{2,3}$ However, the true population prevalence of congenital uterine anomalies is difficult to assess partly because there are no universally agreed standardized classification systems and partly because the best diagnostic techniques are invasive and, therefore, rarely applied to low-risk study populations.

Most of the cases of Mullerian anomalies are either asymptomatic or have subtle gynaecological symptoms. But uterine anomalies are associated with diminished 
cavity size, insufficient musculature, impaired ability to distend, abnormal myometrial and cervical function, inadequate vascularity, and abnormal endometrial development. ${ }^{4}$ Because of these structural limitations, Mullerian anomalies in pregnancy often result abortion, preterm delivery, growth restrictions, malpresentations and ultimately increased rate of caesarean section.

Present study has been undertaken to assess the effects of the various Mullerian anomalies on the outcome of pregnancy in Indian scenario. Even with the advent of superior imaging modalities like 3D ultrasonography, CT scan, MRI etc. Mullerian anomalies remain an incidental diagnosis in majority of cases in India. This may be accounted to the limited resource setup in India and lack of health seeking attitude amongst infertile and reproductively challenged couples.

\section{METHODS}

The proposed study “An Observational Study of Effect of Mullerian Anomalies on Pregnancy was conducted in OBGY department at Lokmanya Tilak Municipal Medical College and General Hospital, a Tertiary Care Medical Centre over a period of two years from January 2015 to December 2017.

The proposed study had a sample size of 30 patients. It was a prospective observational study. Ethical approval of the study protocol was obtained from the ethics committee of institute.

\section{Inclusion criteria}

- All registered or referred ANC patients with diagnosed Mullerian anomalies. Patients with incidental diagnosis of Mullerian anomalies intraoperatively during LSCS.

\section{Exclusion criteria}

- Patients not willing to be included in the study.

- Infertility patients with Mullerian anomalies who have not conceived.

- Patient with severe co morbidities like severe preeclampsia, uncontrolled hypertension, gestational diabetes, maternal cardiovascular disease.

All Mullerian anomalies were classified according to American Society of Reproductive Medicine classification of Mullerian anomalies, 1988. As type I anomaly in ASRM classification is uterine aplasia, no cases were included in this study. The obstetrics profile that is age, parity and no. of previous abortions were studied. Duration of infertility, if any, was also assessed for each Mullerian anomalies.

Since, diagnosing Mullerian anomaly is difficult, timing and diagnostic modalities were studied in detail. Mullerian anomalies cases diagnosed on obstetrics ultrasonography, could not be confirmed on MRI as facility of 1.5 Tesla MRI is not available at our institution. Patients were also enquired about the various gynaecological signs and symptoms, if they experienced any, during their adolescence.

Obstetrics complications of Mullerian anomalies like threatened abortion, preterm delivery and malpresentation were studied diligently in details through indoor records and labor records.

Neonatal outcome was evaluated in form of birth weight and NICU/TCU admissions. All women were subjected to USG KUB postpartum to eliminate any associated renal anomalies.

\section{RESULTS}

A total of 30 cases of Mullerian anomalies in pregnancy were enrolled in this study to analyse the effects on pregnancy and its outcome. Out of the 30 cases, 4 $(13.3 \%)$ were unicornuate uterus, 6 (20\%) uterus didelphys, 2 (6.6\%) uterus bicornuate, 11 (36.6\%) were septate uterus and 7 (23.3\%) arcuate uterus (Table 1).

Table 1: Different Mullerian anomalies studied in pregnancy.

\begin{tabular}{|c|c|c|c|}
\hline \multicolumn{2}{|c|}{ Type of Mullerian Anomalies } & \multicolumn{2}{|l|}{$\begin{array}{l}\text { Total no. } \\
\text { of cases } \\
(n=30)\end{array}$} \\
\hline \multirow{4}{*}{$\begin{array}{l}\text { Type II: } \\
\text { Unicornuate } \\
\text { uterus }\end{array}$} & $\begin{array}{l}\text { A1a: } \\
\text { Communicating } \\
\text { horn (with } \\
\text { endometrial cavity) }\end{array}$ & 00 & 0 \\
\hline & $\begin{array}{l}\text { A1b: Non- } \\
\text { communicating } \\
\text { horn (with } \\
\text { endometrial cavity) }\end{array}$ & 02 & 06.6 \\
\hline & $\begin{array}{l}\text { A2: Horn with no } \\
\text { endometrial cavity }\end{array}$ & 00 & 0 \\
\hline & $\begin{array}{l}\text { B: No rudimentary } \\
\text { horn }\end{array}$ & 02 & 06.6 \\
\hline \multicolumn{2}{|c|}{ Type III: Uterus didelphys } & 06 & 20.0 \\
\hline \multirow{2}{*}{$\begin{array}{l}\text { Type IV: } \\
\text { Uterus } \\
\text { bicornuate }\end{array}$} & $\begin{array}{l}\text { A: Complete till } \\
\text { internal OS }\end{array}$ & 01 & 03.3 \\
\hline & B: Partial & 01 & 03.3 \\
\hline \multirow{2}{*}{$\begin{array}{l}\text { Type V: } \\
\text { Septate } \\
\text { uterus }\end{array}$} & $\begin{array}{l}\text { A: Complete till } \\
\text { internal OS }\end{array}$ & 01 & 03.3 \\
\hline & B: Partial & 10 & 33.3 \\
\hline \multicolumn{2}{|c|}{ Type VI: Arcuate uterus } & 07 & 23.3 \\
\hline \multicolumn{2}{|c|}{ Total } & 30 & 100 \\
\hline
\end{tabular}

All the cases were categorized according to different age groups and $53.3 \%$ (16 cases) belonged to the age group of 20-30 years. $6(20 \%)$ patients were $<20$ years of age and $8(26.6 \%)$ were above 30 years (Table 2). In the present study, majority of the cases $(56.6 \%)$ were either $2^{\text {nd }}$ or $3^{\text {rd }}$ gravida, $6(20 \%)$ were $3^{\text {rd }}$ gravida and above 
and $7(23.3 \%)$ were primigravidas (Table 2). $40 \%$ of the patients had history of abortions. $4(13.3 \%)$ had history of only 1 abortion and $5(16.6 \%)$ had history of 2 abortions (Table 3).

There were $3(10 \%)$ patients who had history 3 or more abortions. These patients were diagnosed as complete bicornuate uterus (Type IV A), complete septate uterus (Type V A) and partial septate uterus (Type V B).

The patient with complete septate uterus was 5 th gravida but had 3 abortions and a preterm delivery resulting in neonatal death. Her present pregnancy also resulted in a preterm breech vaginal delivery at 29 weeks of gestation. Most of the Mullerian anomalies without any cervical or vaginal defect remain asymptomatic, however, often there are subtle gynaecological symptoms.

Most common gynaecological complaint was dysmenorrhea seen in 7 out of 30 cases $(23.3 \%)$, followed by abnormal uterine bleeding, found in 5 out of 30 cases $(16.6 \%) .2$ patients gave history of chronic pelvic pain $(6.6 \%)$ and endometriosis $(6.6 \%)$ each (Table 4).

Table 2: Demographic profile of the patients.

\begin{tabular}{|c|c|c|c|c|c|c|c|}
\hline Age & $\begin{array}{l}\text { Type II: } \\
\text { Unicornuate } \\
\text { uterus }\end{array}$ & $\begin{array}{l}\text { Type III: Uterus } \\
\text { didelphys }\end{array}$ & $\begin{array}{l}\text { Type IV: Uterus } \\
\text { bicornuate }\end{array}$ & $\begin{array}{l}\text { Type V: Septate } \\
\text { uterus }\end{array}$ & $\begin{array}{l}\text { Type VI: } \\
\text { Arcuate }\end{array}$ & $\begin{array}{l}\text { Total } \\
(\mathbf{n}=\mathbf{3 0})\end{array}$ & $\%$ \\
\hline$<20$ years & 01 & 01 & 01 & 02 & 01 & 06 & 20.0 \\
\hline $20-30$ years & 03 & 03 & 00 & 06 & 04 & 16 & 53.3 \\
\hline$>30$ years & 00 & 02 & 01 & 03 & 02 & 08 & 26.6 \\
\hline Total & $04(13.3 \%)$ & $06(20 \%)$ & $02(06.6 \% \%)$ & $11(36.6 \%)$ & $07(23.3 \%)$ & 30 & 100 \\
\hline \multicolumn{8}{|c|}{ Parity wise distribution } \\
\hline Primi gravida & 01 & 04 & 01 & 01 & 00 & 07 & 23.3 \\
\hline $2^{\text {nd }}-3^{\text {rd }}$ gravida & 03 & 01 & 00 & 07 & 06 & 17 & 56.6 \\
\hline$>3$ gravida & 00 & 01 & 01 & 03 & 01 & 06 & 20.0 \\
\hline
\end{tabular}

Table 3: Distribution according to previous pregnancy loss.

\begin{tabular}{|c|c|c|c|c|c|c|c|}
\hline & $\begin{array}{l}\text { Type II: } \\
\text { Unicornuate } \\
\text { uterus }\end{array}$ & $\begin{array}{l}\text { Type III: } \\
\text { Uterus } \\
\text { didelphys }\end{array}$ & $\begin{array}{l}\text { Type IV: } \\
\text { Uterus } \\
\text { bicornuate }\end{array}$ & $\begin{array}{l}\text { Type V: } \\
\text { Septate } \\
\text { uterus }\end{array}$ & $\begin{array}{l}\text { Type VI: } \\
\text { Arcuate }\end{array}$ & $\begin{array}{l}\text { Total } \\
(\mathbf{n}=30)\end{array}$ & $\%$ \\
\hline No. of abortions & 02 & 04 & 01 & 06 & 05 & 18 & 60.0 \\
\hline 1 abortion & 01 & 01 & 00 & 01 & 01 & 04 & 13.3 \\
\hline 2 abortions & 01 & 01 & 00 & 02 & 01 & 05 & 16.6 \\
\hline 3 or $>3$ abortions & 00 & 00 & 01 & 02 & 00 & 03 & 10.0 \\
\hline Total & $4(13.3)$ & $6(20)$ & $2(06.6)$ & $11(36.6)$ & $7(23.3)$ & 30 & 100 \\
\hline
\end{tabular}

Table 4: History of gynaecological complaints.

\begin{tabular}{|c|c|c|c|c|c|c|c|c|}
\hline \multicolumn{2}{|c|}{ Gynaecological symptoms } & $\begin{array}{l}\text { Type II: } \\
\text { Unicornuate } \\
\text { uterus }\end{array}$ & $\begin{array}{l}\text { Type III: } \\
\text { Uterus } \\
\text { didelphys }\end{array}$ & $\begin{array}{l}\text { Type IV: } \\
\text { Uterus } \\
\text { bicornuate }\end{array}$ & $\begin{array}{l}\text { Type V: } \\
\text { Septate } \\
\text { uterus }\end{array}$ & $\begin{array}{l}\text { Type VI: } \\
\text { arcuate }\end{array}$ & Total & $\%$ \\
\hline \multicolumn{2}{|c|}{ No symptoms } & 02 & 03 & 00 & 09 & 07 & $21 / 30$ & 70.0 \\
\hline \multicolumn{2}{|c|}{ Chronic pelvic pain } & 00 & 01 & 01 & 00 & 00 & $02 / 30$ & 06.6 \\
\hline \multicolumn{2}{|c|}{ Dysmenorrhea } & 02 & 01 & 02 & 02 & 00 & $07 / 30$ & 23.3 \\
\hline \multicolumn{2}{|c|}{ AUB } & 00 & 02 & 02 & 01 & 00 & $05 / 30$ & 16.6 \\
\hline \multicolumn{2}{|c|}{ Endometriosis } & 00 & 01 & 01 & 00 & 00 & $02 / 30$ & 06.6 \\
\hline \multirow{2}{*}{ Infertility } & $<5$ years & 01 & 02 & 01 & 02 & 00 & $06 / 30$ & 20.0 \\
\hline & $>5$ years & 00 & 01 & 01 & 00 & 00 & $02 / 30$ & 06.6 \\
\hline
\end{tabular}

All the patients were enquired if they had any history of infertility (including both primary or secondary infertility) and undergone any kind of evaluation or treatment for infertility. Only $8(26.6 \%)$ patients confirmed that they had history of infertility, out of which $2(6.6 \%)$ had history of infertility of more than 5 years (Table 4). These two cases belonged to category of uterus didelphys (Type III) and partial bicornuate uterus (Type IV B). $56.6 \%$ of Mullerian anomalies in this study were 
diagnosed incidentally during LSCS. 13 cases (43.4\%) were diagnosed either on HSG, USG or MRI (Figure 1). 8 cases $(26.6 \%)$ were diagnosed on USG, 6 during pregnancy and 2 prenatally. 3 cases (10\%) were diagnosed on MRI.

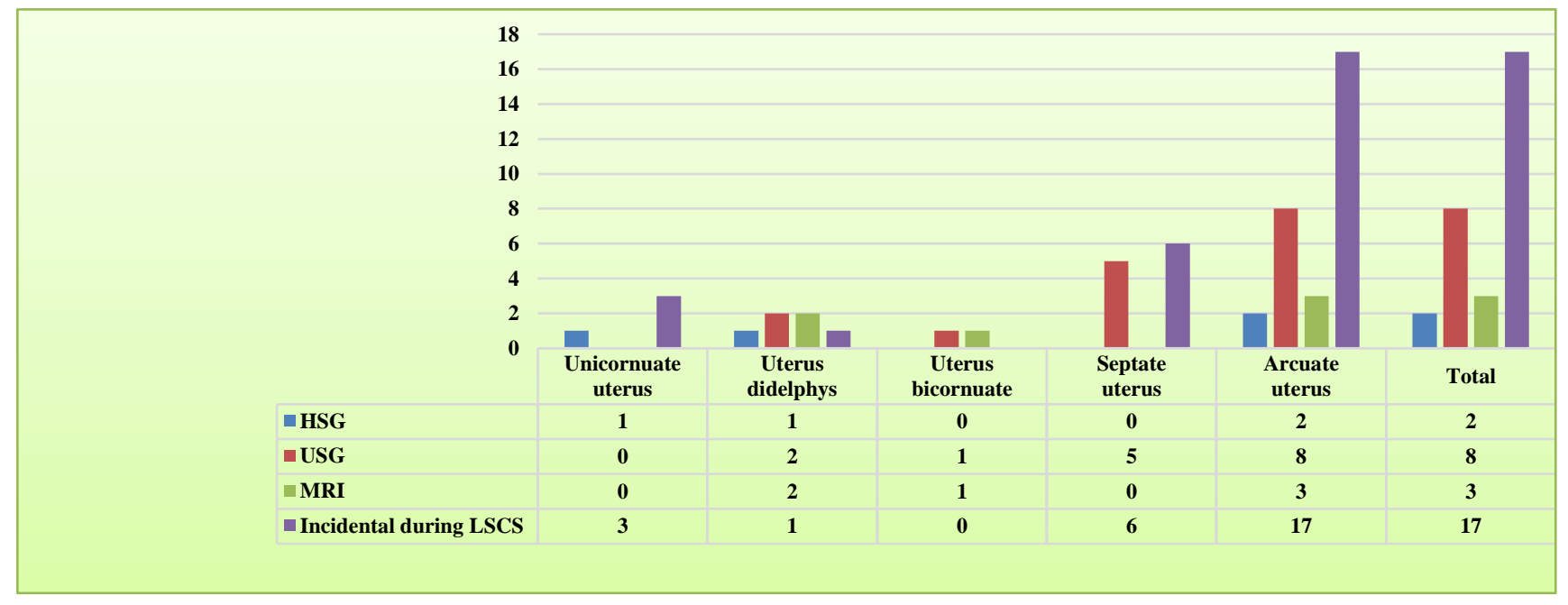

Figure 1: Diagnostic modalities.

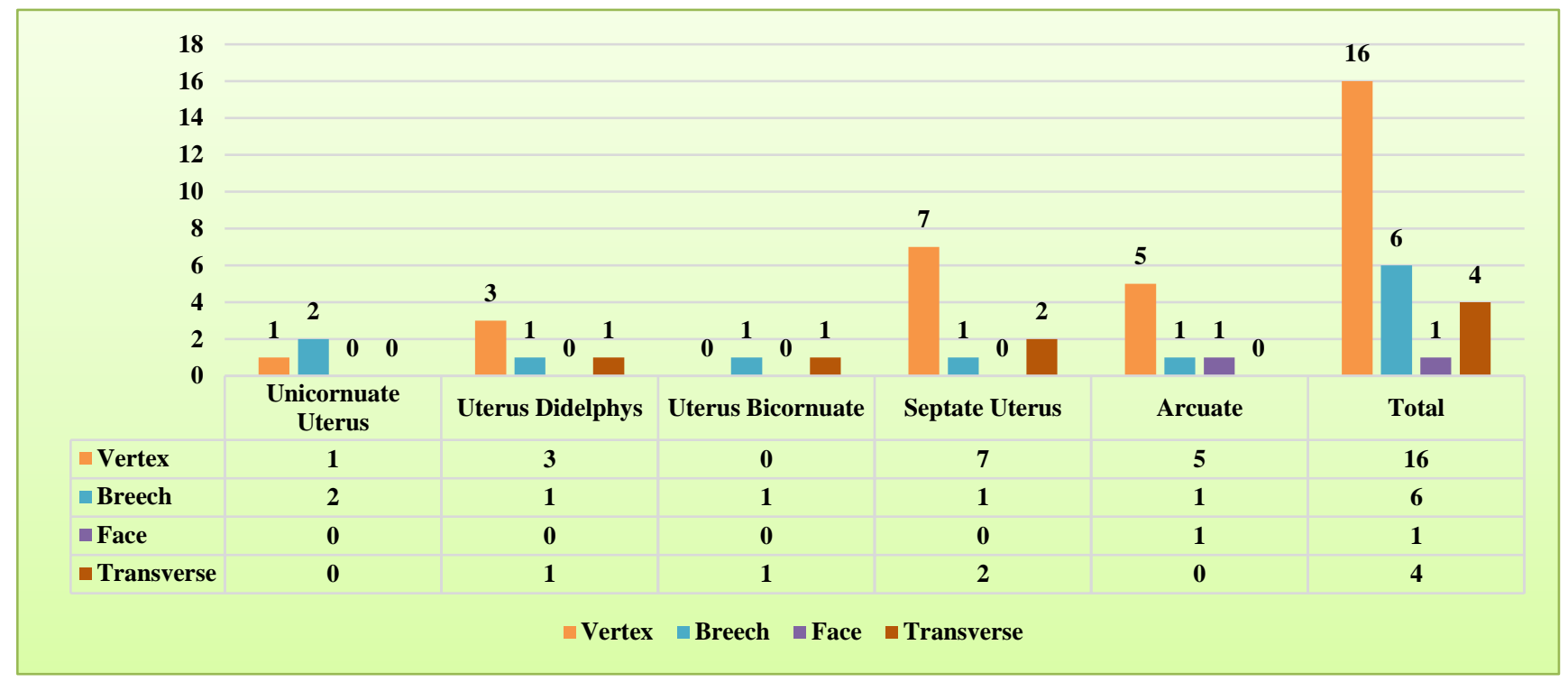

Figure 2: Distribution according to the presentation.

All these 3 cases were primigravidas with history of infertility. 2 cases $(6.6 \%)$ were diagnosed on HSG as a part of their infertility workup.

These cases were unicornuate uterus with no horn (Type II B) and uterus didelphys (Type III). As malpresentation was the most common obstetric complication in this study (Table 5). A detailed analysis various presentation in different category of Mullerian anomalies was done. Vertex was the most common presenting part, seen in 16 out of 30 cases $(53.3 \%)$. It includes all the positions (Figure 2). There was only 1 case of deep transverse arrest seen in G2P1IUFD1 with partial septate uterus (Type V B). Most common malpresentation encountered was breech, a total of 6 out of 30 cases $(20 \%)$ followed by Transverse lie $(13.3 \%)$ and face presentation $(03.3 \%) .19$ out of $30(63.3 \%)$ patients included in this study underwent LSCS (Table 6). Most common indication for LSCS was malpresentation, seen in 10 out 19 cases $(52.6 \%) .2$ out of 19 LSCS $(10.5 \%)$ were done electively for infertility conception in a diagnosed of Mullerian anomalies. Normal delivery was done only in 7 cases out of the total 30 cases $(23.3 \%)$. Forceps delivery was seen in a single case $(3.3 \%)$ of partial septate uterus 
(Type V B). Forceps were applied for foetal distress in a 2nd stage of labour. As malpresentation was the most common obstetric complication in this study. A detailed analysis various presentation in different category of
Mullerian anomalies was done. Vertex was the most common presenting part, seen in 16 out of 30 cases $(53.3 \%)$. It includes all the positions (Figure 2).

Table 5: Obstetrics complications.

\begin{tabular}{|c|c|c|c|c|c|c|c|}
\hline $\begin{array}{l}\text { Obstetrics } \\
\text { complications }\end{array}$ & $\begin{array}{l}\text { Type II: Uni } \\
\text { cornuate } \\
\text { uterus }(\%)\end{array}$ & $\begin{array}{l}\text { Type III: } \\
\text { Uterus } \\
\text { didelphys } \\
(\%)\end{array}$ & $\begin{array}{l}\text { Type IV: } \\
\text { Uterus bi } \\
\text { cornuate }\end{array}$ & $\begin{array}{l}\text { Type V: } \\
\text { Septate } \\
\text { uterus }\end{array}$ & $\begin{array}{l}\text { Type VI: } \\
\text { Arcuate uterus } \\
(\%)\end{array}$ & $\begin{array}{l}\text { Total } \\
(n=30)\end{array}$ & $\%$ \\
\hline $\begin{array}{l}\text { Threatened } \\
\text { abortion }\end{array}$ & $02 / 04(50)$ & $03 / 06(50)$ & $00 / 02(0)$ & $02 / 11(18.1)$ & 00/07 (00.0) & $07 / 30$ & 23.3 \\
\hline Abortion & $01 / 04(25)$ & $01 / 06(16.6)$ & 00/02 (0) & 01/11 (09.0) & 00/07 (00.0) & $03 / 30$ & 10 \\
\hline Preterm delivery & $00 / 04(0)$ & $02 / 06(33.3)$ & $01 / 02(50.0)$ & $02 / 11(18.1)$ & $01 / 07(14.2)$ & $06 / 30$ & 20 \\
\hline Malpresentation & $02 / 04(50)$ & $02 / 06(33.3)$ & $02 / 02(44.4)$ & $03 / 11(27.2)$ & $02 / 07(28.5)$ & $11 / 30$ & 36.6 \\
\hline Rupture & $01 / 04(25)$ & $00 / 06(0.0)$ & $00 / 09(0)$ & $00 / 11(00)$ & $00 / 07(00.0)$ & $01 / 30$ & 03.3 \\
\hline No complication & 00/04 (0) & 01/06 (16.6) & 00/09 (00.0) & 07/11 (63.6) & $04 / 07(57.1)$ & $12 / 30$ & 40 \\
\hline
\end{tabular}

Table 6: Mode of delivery.

\begin{tabular}{|c|c|c|c|c|c|c|c|}
\hline $\begin{array}{l}\text { Mode of } \\
\text { delivery }\end{array}$ & $\begin{array}{l}\text { Type II: Uni } \\
\text { cornuate uterus }\end{array}$ & $\begin{array}{l}\text { Type III: } \\
\text { Uterus } \\
\text { didelphys }\end{array}$ & $\begin{array}{l}\text { Type IV: } \\
\text { Uterus } \\
\text { bicornuate }\end{array}$ & $\begin{array}{l}\text { Type V: } \\
\text { Septate } \\
\text { uterus }\end{array}$ & $\begin{array}{l}\text { Type VI: } \\
\text { Arcuate } \\
\text { uterus }\end{array}$ & $\begin{array}{l}\text { Total } \\
(\mathbf{n}=30)\end{array}$ & $\%$ \\
\hline Abortion & 01 & 01 & 00 & 01 & 00 & 03 & 10 \\
\hline Normal & 00 & 03 & 01 & 03 & 00 & 07 & 23.3 \\
\hline Forceps & 00 & 00 & 00 & 01 & 00 & 01 & 03.3 \\
\hline LSCS & 03 & 02 & 01 & 06 & 07 & 19 & 63.3 \\
\hline Total & $04(13.3 \%)$ & $06(20 \%)$ & $02(06.6 \%)$ & $11(36.6 \%)$ & $07(23.3 \%)$ & 30 & 100 \\
\hline
\end{tabular}

There was only 1 case of deep transverse arrest seen in G2P1IUFD1 with partial septate uterus (Type V B). Most common malpresentation encountered was breech, a total of 6 out of 30 cases (20\%) followed by Transverse lie $(13.3 \%)$ and face presentation $(03.3 \%) 19$ out of 30 $(63.3 \%)$ patients included in this study underwent LSCS (Table 6).

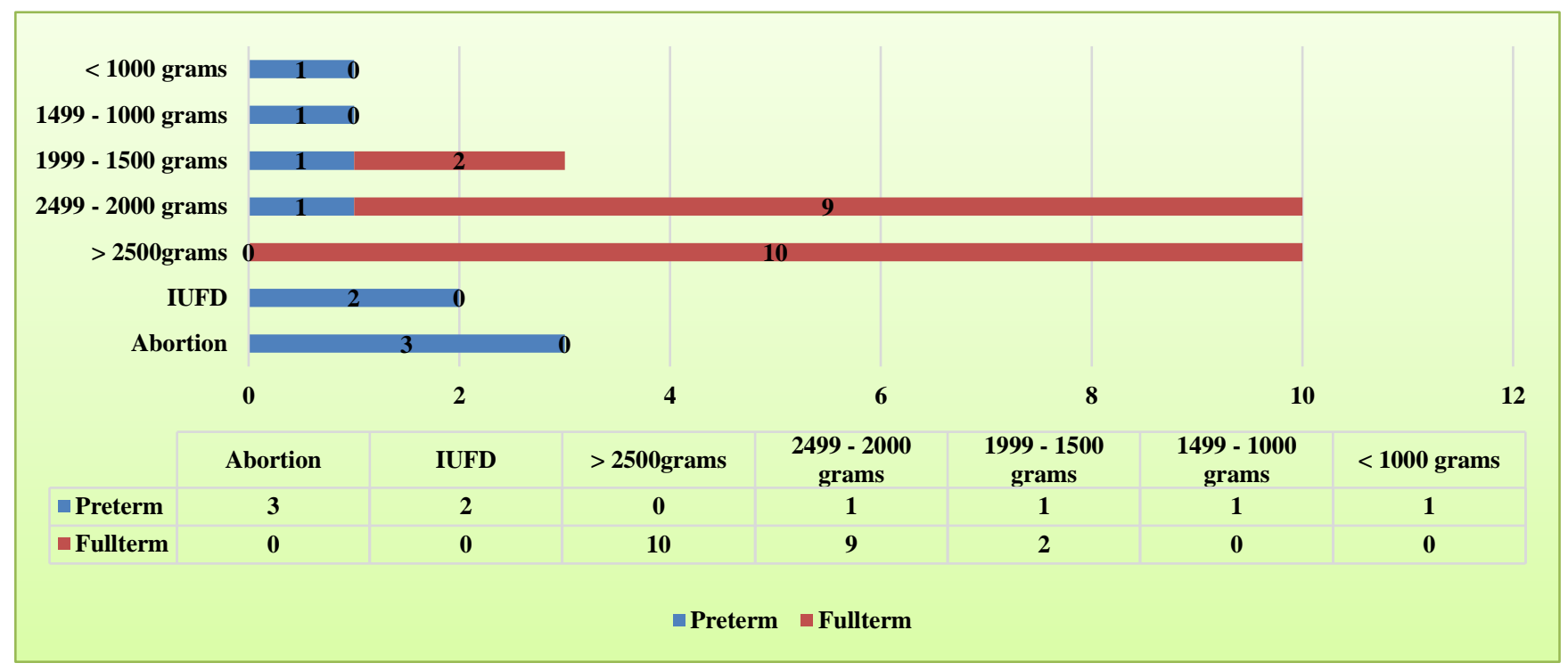

Figure 3: Distribution according to the foetal outcome. 
Most common indication for LSCS was malpresentation, seen in 10 out 19 cases $(52.6 \%) .2$ out of 19 LSCS $(10.5 \%)$ were done electively for infertility conception in a diagnosed of Mullerian anomalies. Normal delivery was done only in 7 cases out of the total 30 cases $(23.3 \%)$. Forceps delivery was seen in a single case $(3.3 \%)$ of partial septate uterus (Type V B). Forceps were applied for foetal distress in a 2nd stage of labour. Neonatal outcome has been described in terms of foetal weight, term or preterm delivery. There were 2 IUFDs (6.6\%) in the study, both were preterm belonging to uterus didelphys (Type III) and complete bicornuate uterus
(Type IV A). There were 3 abortions (09.9\%). 21 out of 30 deliveries were full term, whereas there were 4 preterm live births (Figure 3). 15 out of 25 live births were low birth weight. Mullerian anomalies are often associated with renal anomalies. So, all the patients were subjected to an USG KUB to look for any renal anomaly. There was no renal anomaly in $73.3 \%$ (22 out of 30 cases) of cases. Unilateral renal atresia was the commonest renal anomaly with the incidence of $13.3 \%$ (4 out of 30 cases) followed by ectopic kidney with the incidence of $10 \%$ (3 out of 30 cases) (Table 7). There was only one case of horseshoe kidney $(3.3 \%)$ seen with complete bicornuate uterus (Type IV A).

Table 7: Associated renal anomalies.

\begin{tabular}{|c|c|c|c|c|c|c|c|}
\hline Renal anomalies & $\begin{array}{l}\text { Type II: Uni } \\
\text { cornuate } \\
\text { uterus }\end{array}$ & $\begin{array}{l}\text { Type III: } \\
\text { Uterus } \\
\text { didelphys }\end{array}$ & $\begin{array}{l}\text { Type IV: } \\
\text { Uterus } \\
\text { bicornuate }\end{array}$ & $\begin{array}{l}\text { Type V: } \\
\text { Septate } \\
\text { uterus }\end{array}$ & $\begin{array}{l}\text { Type VI: } \\
\text { Arcuate } \\
\text { uterus }\end{array}$ & $\begin{array}{l}\text { Total } \\
(n=30)\end{array}$ & $\%$ \\
\hline No Anomaly & 03 & 03 & 00 & 10 & 06 & 22 & 73.3 \\
\hline Unilateral renal agenesis & 01 & 02 & 01 & 00 & 00 & 04 & 13.3 \\
\hline Horseshoe kidney & 00 & 00 & 01 & 00 & 00 & 01 & 03.3 \\
\hline Ectopic kidney & 00 & 01 & 00 & 01 & 01 & 03 & 10.0 \\
\hline Total & $04(13.3 \%)$ & $06(20 \%)$ & $02(06.6 \%)$ & $11(36.6 \%)$ & $07(23.3 \%)$ & 30 & 100 \\
\hline
\end{tabular}

\section{DISCUSSION}

In the present study incidence could not be calculated due to limited resources and time. However, a differential incidence has been provided within the sample size of 30 in this study. The most common anomaly encountered in the study was Type VB (10) that is partial septate uterus followed by Arcuate uterus. A metanalysis of 94 studies comprising of 89861 women was published in oxford journal to study the prevalence of congenital uterine anomalies in unselected and high-risk populations. ${ }^{5}$ The prevalence of Mullerian anomalies was $5.5 \%$ in the low risk population, $8.0 \%$ in women with infertility, $13.3 \%$ in those with a recurrent pregnancy loss and $24.5 \%$ in those with both RPL and infertility. Arcuate uterus is most common in the unselected population (3.9\%), and its prevalence is not increased in high-risk groups..$^{5}$ In contrast, septate uterus is the most commonly associated with obstetrics complication. Mullerian anomalies are often associated with recurrent miscarriages. ${ }^{6}$ In the present study, $40 \%$ of patients had history of one or more abortions and $26.6 \%$ cases had two or more abortions. Moreover, $10 \%$ of pregnancies enrolled in this study also ended up as abortions. A metanalysis of 9 studies, published in journal of ultrasound in obstetrics and gynecology, documented that there is increased relative risk by 2.89 time of first trimester abortions in Mullerian anomalies. ${ }^{7}$ Subgroup analysis showed that women with either subtype of canalization defect (sub septate or septate) have the maximum risk of first-trimester miscarriage. As present study was not a cohort study, author cannot comment on the relative risk, however, an increased rate of abortion was reported in all the categories of Mullerian anomalies. Subtle Mullerian anomalies are difficult to diagnose. HSG gives a view of the endometrial cavity but does not visualize the fundus and the uterine contour and is invasive. 2D ultrasonography gives a fair idea about the external contour of the uterus but might fail to visualize some lateral fusion defects. Magnetic resonance imaging (MIR) allowed for the avoidance of these issues while offering accuracy, thus becoming the gold standard diagnostic imaging modality. ${ }^{8}$ Moreover, only 1.5 Tesla MRI can be used for diagnosing Mullerian anomalies in pregnancy which might be unavailable at some centre. These shortcomings of diagnosing modalities lead to a high rate (56.6\%) of incidental diagnosis of Mullerian anomalies in the present study. In a recent study, it was found that $3 \mathrm{D}$ ultrasonography has accuracy similar or higher than MRI. ${ }^{9}$ Although many women with Mullerian anomalies are asymptomatic, several gynecologic signs and symptoms are associated with specific anomalies. Fedele et al in 2006 found increased menstrual complaints in diagnosed cases of septate uterus $10.30 \%$ of patients in the study had gynecological complaints, most common being dysmenorrhea seen in $23.3 \%$ cases. Grimbizis et al. published a metanalysis studying 30 research papers on reproductive outcome in patients with Mullerian anomalies. In the present study maximum abortion rate was seen in unicornuate uterus but in the Grimbizis' metanalysis maximum abortion rate was seen in septate uterus. ${ }^{11}$ This discrepancy can be attributed to the fact that most of the septate uterus studied in this research was partial in nature. Secondly, the sample size of unicornuate 
uterus is too sample to be compared with result of the metanalysis. Preterm delivery rate is $20 \%$ in this study as compared to $39.3 \%$ preterm delivery rate reported in Hua et al. ${ }^{12}$ Most of the research papers on reproductive outcomes in Mullerian anomalies stated that malpresentation was a common and a consistent complication associated with all Mullerian anomalies except arcuate uterus. Malpresentation was seen in $36.7 \%$ of cases in the present study. The current study reported a very high rate of caesarean section rate of $63.3 \%$ as compared to $34.7 \%$ in Hua et al. ${ }^{12}$ This high rate can be justified by the fact $56.6 \%$ of cases included in this study were diagnosed incidentally during LSCS. Nagarathnamma et al published a paper on pregnancy outcome in uterine anomalies with a sample size of 10 . They reported a very high pregnancy rate of $80 \% .^{13}$ Mullerian anomalies are often associated with renal anomalies owing to embryological association of the urinary and reproductive system due to a close embryological association between them. ${ }^{14,15} 26.7 \%$ cases had renal anomalies in the present study. These renal anomalies are often asymptomatic and may not have any significance in the pregnancy. However, for the complete documentation of the anomaly a detailed ultrasonography of the abdomen should be done to rule out renal agenesis, ectopic kidney, defect in ureteric system, horse shoe kidney etc.

\section{CONCLUSION}

The major concern which this study raises is the difficulty to diagnose Mullerian anomalies. It is observed that due to the asymptomatic course of Mullerian anomalies, invasive nature of HSG and lack of 1.5 Tesla MRI at many institutes leads to low rate of diagnosis of Mullerian anomalies. The study establishes that pregnancy with Mullerian anomalies often have preterm delivery, IUGR and malpresentation. These might result in a higher risk of caesarean delivery. Patients with Mullerian anomalies should have a detailed counselling session with senior obstetrician and consultants about all the anticipated maternal and neonatal complications.

Funding: No funding sources Conflict of interest: None declared

Ethical approval: The study was approved by the Institutional Ethics Committee

\section{REFERENCES}

1. Amesse LS, Pfaff-Amesse T. Congenital anomalies of the reproductive tract. In Clinical Reproductive Medicine and Surgery (1st edn) Falcone T, Hurd WW (eds). Mosby: New York, NY.2007;171--190.

2. Acien P. Incidence of mu "llerian defects in fertile and infertile women. Hum Reproduct. 1997;12(7):1372-6.
3. Simón C, Martinez L, Pardo F, Tortajada M, Pellicer A. Müllerian defects in women with normal reproductive outcome. Fertil Steril. 1991;56(6):11923.

4. Rock J A,Schlaff W D.The obstetric consequences of uterovaginal anomalies. Fertil Steril 1985;43(5):68192.

5. Chan YY, Jayaprakasan K, Zamora J, Thornton JG, Raine-Fenning N, Coomarasamy A. The prevalence of congenital uterine anomalies in unselected and high-risk populations: a systematic review. Human Reproduct Update. 2011;17(6):761-71..

6. Jaslow CR, Kutteh WH. Effect of prior birth and miscarriage frequency on the prevalence of acquired and congenital uterine anomalies in women with recurrent miscarriage: a cross-sectional study. Fertil Steril. 2013;99(7):1916-22.e1.

7. Chan YY, Jayaprakasan K, Tan A, Thornton JG, Coomarasamy A, Raine-Fenning NJ. Reproductive outcomes in women with congenital uterine anomalies: a systematic review. Ultrasound Obstet Gynecol. 2011;38(4):371-82.

8. Berger A, Batzer F, Lev-Toaff A, Berry-Roberts C. Diagnostic imaging modalities for Müllerian anomalies: the case for a new gold standard. J Minim Invasive Gynecol. 2014;21(3):335-45.

9. Ergenoglu AM, Sahin Ç, Şimşek D, Akdemir A, Yeniel AÖ, Yerli H, Sendag F. Comparison of threedimensional ultrasound and magnetic resonance imaging diagnosis in surgically proven Müllerian duct anomaly cases. Eur J Obstet Gynecol Reprod Biol. 2016;197:22-6.

10. Fedele L, Bianchi S, Frontino G. Septums and synechiae: approaches to surgical correction. Clin Obstet Gynecol. 2006;49(4):767-88.

11. Grimbizis GF, Camus M, Tarlatzis BC, et al. Clinical implications of uterine malformations and hysteroscopic treatment results. Hum Reprod Update. 2001;7(2):161-74.

12. Hua M, Odibo AO, Longman RE, et al. Congenital uterine anomalies and adverse pregnancy outcomes. Am J Obstet Gynecol 2011;205(6):558.e1-5.

13. Nagarathnamma R, James T, Prasad N. Pregnancy Outcome in uterine anomalies. J Med Sci 2017;3(1):31-3.

14. Li S, Qayyum A, Coakley FV, Hricak H. Association of renal agenesis and mullerian duct anomalies. J Comput Assist Tomogr. 2000;24(6):829-34.

15. Hall-Craggs MA, Kirkham A, Creighton SM. Renal and urological abnormalities occurring with Mullerian anomalies. J Pediatr Urol. 2013;9(1):2732 .

Cite this article as: Raj N, Chavan NN. An observational study of effect of Mullerian anomalies on pregnancy. Int J Reprod Contracept Obstet Gynecol 2019;8:1155-61. 